\title{
An examination of coping strategies used by long-term cancer survivors
}

by Maureen A. Cava

\section{Abstract}

Little research has been conducted in the area of long-term psychosocial adjustment in cancer patients. In a qualitative study of five long-term survivors, various coping strategies are suggested as a way of dealing with this life-threatening disease. The Neunan Systems Model (1989) was used as a theoretical basis for this research. The findings also support the current literature that fear of recurrence and uncertainty of the future are major concerns for survivors.

\section{Introduction}

Until now, most nursing literature in the area of oncology has focused on cancer as a disease. This narrow focus on the physical and psychological aspects of the disease has been documented in several reviews (Fernsler, Holcombe, and Pulliam, 1984; Grant and Padilla, 1983; and Scott, 1985). However, at a time when quality of life is emerging as an important consideration, this focus seems increasingly inappropriate. Leigh (1989) argues that those affected by cancer, caregivers and survivors alike, should be equipped to deal with a wide range of concerns including nutrition, treatment options, stress reduction, peer support, late effects and discrimination.

This descriptive study investigated how long-term cancer survivors used specific coping strategies in order to begin reconstitution and regain wellness. For the purpose of the study, coping strategies are the conscious and unconscious ways of dealing with stressors to retain, attain, or maintain system integrity (Neuman, 1989). There are a growing number of individuals who are surviving the diagnosis of cancer. Attention needs to be paid to quality-of-life issues surrounding survivorship. Knowledge of specific coping strategies which survivors used at different times during the cancer experience may assist others as they adjust to the illness. Cancer survivors can also assist health care professionals to provide effective individualized care to those affected by this life-threatening illness.

With so many individuals surviving cancer, there is an urgency for nursing to address the different sequelae accompanying life after cancer. Survivors of cancer are the best source to enhance understanding of the effect of stress related to cancer. By listening to these individuals, health care Maureen A. Cava professionals will be in a better position to understand and assist people with cancer through diagnosis, treatment and follow-up.

\section{Background literature}

Carter (1989) notes that research on cancer survivorship completed between 1975 and 1982 is limited to issues of interpersonal and emotional needs. She cites only three studies which address the long-term psychological adjustment of adults who have the cancer experience. Long-term as defined in her research is a survivor who has lived five years past the point of diagnosis without recurrence.

Fisher's (1979) descriptive study explored the psychosocial adjustment following total pelvic exenteration. The results of her research showed that problems of body image, social lifestyle and sexual relations/practices were apparent in the six women she interviewed. Her study also indicated ways in which nurses could assist with the adjustment of these individuals as they redevelop their lives.

Thorne (1985) found that individuals who survive cancer do experience some difficulties in their lives after cancer. Her participants described helpful or supportive health care behaviours which facilitated the recovery process. The individuals in Thorne's study felt that the transition to wellness may be tangible or symbolic but is uniquely defined by the individual. These persons with cancer felt that their own approaches and attitudes, as well as those of the health care providers, were important in determining the quality of life after cancer.

Carter (1989) studied 25 women who had survived breast cancer. Her findings suggest a theme of "going through" which involved movement through several phases of surviving, some of which occurred simultaneously. The phases were labelled: Interpreting the diagnoses, confronting mortality, reprioritizing, coming to terms, moving on and flashing back.

Gerlach et al. (1990) surveyed survivors who attended a National Survivors' Day. These survivors expressed interest in prevention/detection programs, psychosocial issues such as family and physician communications, economic issues, and peer support groups.

Dirkson (1989) examined the well-being of 31 survivors of malignant melanoma. She found that cancer survivors engaged in specific actions which they thought would decrease the chances of recurrence, including healthy eating, exercise, attitude and change of lifestyle. She suggested that nurses need to support and enhance individual beliefs regarding control over a stressful life event, which includes educating patients on how they can decrease the chance of recurrence and promoting activities which assist in restoring self-esteem and thereby increase perceived well-being.

\section{UNE ÉTUDE DES STRATÉGIES D'ADAPTATION EMPLOYÉES PAR LES SURVIVANTS À LONG TERME DU CANCER}

\section{ABRÉGÉ}

Peu de recherches ont été faites dans le domaine de l'adaptation psychosociale à long terme des patients souffrant du cancer. Cette étude qualitative portant sur cinq survivants à long terme suggère diverses stratégies d'adaptation qui permettent de faire face à cette maladie mortelle. Le Neuman Systems Model a servi de base thérique pour la présente recherche. Les résultats se font l'écho des articles spécialisés actuels quand ils montrent que la peur d'une rechute et l'incertitude quand à l'avenir sont deux des inquiétudes principales des survivants.

Maureen Cava RN, MSN, is Clinical Nurse Specialist, Education and Research Division, North York Public Health Dept., North York, Ontario. She received the Canadian Cancer Society Maurice Legault Fellowship Award 1989 and the Canadian Federation of University Women Alice E. Wilson Award, also in 1989. 
Although limited in scope, the literature suggests that cancer survivors can articulate the physical and psychosocial issues related to surviving cancer, as well as offer some specific actions for decreasing the chance of recurrence.

\section{Purpose and methods}

The present study was designed to augment nursing literature on long-term survivorship by investigating specific coping strategies survivors employ in living with cancer. The Neuman Systems Model Assessment and Intervention Tool (Neuman, 1989) was adapted for use as the interview guide for this research (see Figure One).

\section{Methodology}

Three female and two male cancer survivors were interviewed for this qualitative study. Individuals who were beyond the five-year point of diagnosis without recurrence were initially approached by the head nurse of the oncology clinic of a small urban hospital in southern Ontario. The names of those interested were given to the researcher to contact and discuss the study further. Five participants ranging in age from 34 to 64 years with survival time from five to 27 years were interviewed for the study.

A semi-structured interview guide based on Neuman's (1989) model was used to elicit information related to coping strategies (sec Figure 1). A brief demographic questionnaire was also included. An expert oncology nurse reviewed the questions for content and validity. A pilot test of the interview guide was done with an individual who is a cancer survivor and was known to the researcher. This determined if the questions were understandable, should be changed and could be answered within the allotted time frame.

By conducting interviews, the researcher was attempting to find out what experience and meanings embody the everyday life of the cancer survivor. The task of the researcher was to uncover meanings in such a way that they were not destroyed, distorted, decontextualized, trivialized, or sentimentalized (Benner, 1985). The cancer survivor offered a depiction of the lived experience, and the researcher analyzed these for commonalities in meanings, situations, practices, and bodily experiences.

The interviews were audiotaped. Using transcriptions of the tapes, answers to each of the nine interview questions were summarized. The data in relation to the coping strategies was coded and summarized in tables enabling themes to be easily identified.

\section{Findings}

Analysis of the responses to the nine interview questions is discussed. Through this analysis, commonalities and differences between survivors are noted. The particular strategies that were used by the survivors interviewed are identified, summarized and discussed.

\section{Major stress area or problem}

A common theme which surfaced from the interviews was the anxiety and uncertainty of having cancer. The feelings of anxiety and uncertainty occurred at different times in the cancer experience, but most often at initial diagnosis, prior to check-ups, or on finding a physical change which they perceived as being abnormal. These feelings are reflected in statements such as: "I just prayed that I would see the children grow up;" and "the only time I'm concerned about stress would be when I start to think about going for my check-ups."

\section{Coping strategies}

Each of the survivors' experiences with cancer was different. The differences emerged not only in relation to the length of time from diagnosis, but also in terms of the type of cancer and treatment received by each. Whether coping strategies and adjustment processes would be different for individuals who had similar cancers and treatment or whether increasing the sample size would further delineate the types of strategies used and identify others is not known. This may account for the differing coping strategies which were used to adjust to the cancer at the different trajectory points.

During the diagnostic period faith played an important role for some. For others, diagnosis brought anxiety which encouraged one person to get more information and to have "read about the cancer and found out that there was a pretty good prognosis." Another just "got hold of my bootstraps and away I went." Fears and worries were also apparent during diagnosis and evidenced in statements like: "I was very, very worried," and "I just felt crushed."

During the treatment phase, keeping a positive morale seemed to assist most of the survivors to cope. "I kept a pretty good morale once I got hold of myself" was indicative of this attitude. Distractions such as going to a friend's cottage, or just being able to go out with friends were helpful for some as well.

After treatment was completed there were similarities noted in the coping strategies used. Having the ability to accept the support from family, friends, and coworkers seemed to be a positive coping strategy. One felt that, "being accepted as I was with hairpiece and all when I went back to work," and "being accepted at my service club with open arms" were very important. Distraction in the form of seeing family, and "going north on vacation and that's how I coped" were also important.

The survivors interviewed for this study cope presently with the cancer by helping others who have been similarly diagnosed. One "concentrates lots of time with cancer patients" where she feels she gains strength and this is, in effect, "her support system." For another, becoming a volunteer for the Canadian Cancer Society helped her: "In a way, it's kept me involved." Not dwelling on the cancer and focusing on activities which are distracting were also mentioned as ways to cope in their present lifestyle.

To cope with the uncertainties of cancer, all survivors have participated in the recovery process by keeping their follow-up appointments. This gives them reassurance that the cancer has not come back, and that they may continue with things as they had been doing.

\section{Changes in lifestyle}

One variation in patterns that emerged from the study data was the survivors' perceptions of whether having cancer had changed their lives. Only one participant commented on the difference in her life since being diagnosed with cancer. She articulated, "cancer gave me a different direction. Through having cancer, I've broadened myself. Although I'm not comfortable speaking in public, I've forced myself to do it." The other survivors felt their present lifestyle did not change just because of the diagnosis of cancer.

\section{Figure One: Research Questions}

1. What do you consider your major problem, stress area, or areas of concern since your diagnosis of cancer?

2. How did you cope:

(a) when the diagnosis of cancer was made,

(b) during treatment,

(c) following treatment and

(d) presently?

3. How does your present lifestyle differ from your precancer lifestyle?

4. Have you ever experienced a major problem comparable to cancer that caused you stress or concern?

5 . How did you cope with this?

6. Were the coping strategies used successful?

7. What do you anticipate in the future as a consequence of having survived cancer?

8. What are you doing to cope with these potential consequences? 9. What do you expect others to do for you?

Adapted from The Neuman System Model (2nd Ed.) (p. 61-62) by B. Neuman, 1989, Norwalk: Appleton and Lange. 
However, when analyzing strategies that these individuals are using to deal with the cancer experience, they identified changes in their lifestyles which have been positive and occurred as a result of having cancer. Supporting others who are undergoing a similar situation was a way of doing this for the other survivors. "I just talk to them, and if I think it's going to do them any good, I'll tell them what's happened to me. It helps me too."

\section{Other stresses and coping strategies used}

For two of the survivors, having cancer was the most stressful event that they had to deal with thus far. For another, a situation which occurred to another member of her family was as stressful, if not more so, than having been diagnosed herself. She felt she didn't cope as well in this situation as it was "out of my hands." With the cancer she felt she had control and "could make the decisions." A major stressor for the other two survivors was having another serious medical problem in their younger years. To cope with these circumstances each sought medical advice and received support from their families.

\section{Views of the future}

The possibility of having a recurrence of or dying from the cancer was a common theme in discussions regarding the future. "I think I am going to have to watch the rest of my life" and, "The possibility of my dying of cancer is probably fairly great" are suggestive of this. One of the survivors viewed the future in a more positive manner and wanted to have a "better understanding of cancer."

Each one of the survivors differed in the way they planned to cope with the possible threat of recurrence. For one, using denial in the form of "I have a mental block about it" seems to work. Attending follow-up appointments regularly and practising self-care strategies such as breast self-examination were also suggested. Going for check-ups "helps us keep things under control." Seeking information was yet another way of gaining a better understanding of the disease and thus helping to cope in the future.

\section{Expectations of support from others}

All survivors interviewed expected more support from their professional caregivers rather than from family and friends. Their comments relating to expectations from caregivers ranged from "You expect competent care in the hospital," to "l expect caregivers to tell me everything that's wrong." Still others stated that "Caregivers should be knowledgeable about the specific situation, including all the latest techniques, prognosis, and everything," and that the individual should "have confidence in the caregivers."

The participants agreed that they received support from family and friends, although they had no expectations that this should happen. Friends would come and do things for them, or just show up to help out. It was important to know that friends were "thinking about me" and that they were "just normal and being my friends."

\section{Discussion}

The findings from this study are similar to other works which are reported in the literature.

In Thorne's (1985) study, many of the participants explained that one of the factors which determined how they move toward wellness was the extent of the person's involvement in managing the cancer. This involvement included faith, humour, and the will to live. Similar strategies were used by several of the survivors interviewed in the present study. Thorne also suggested that survivors pass through stages and begin to put the cancer in the background. Getting back to a normal lifestyle either by working, caring for children, travelling, volunteering, or other activities which were part of their precancer lifestyle were seen as important in the present study.

Dirkson (1989) found that survivors of melanoma expressed control over their cancer by engaging in actions such as exercise, healthy eating, change in lifestyle, and attitude. Having a positive attitude was a similar finding of this study. The other common finding was the change in lifestyle for one of the survivors. The other participants suggested that their precancerous lifestyle did not change dramatically.

Several authors have reported that personal control and active involvement are key to the quality of life in all stages of the cancer experience (Cantor, 1978: Lewis, 1982; Lewis et al., 1986; Sourkes, 1982; Thorne, 1985; and Weisman, 1979). These findings were also true of the cancer survivors interviewed in this study. Coping strategies of seeking medical advice if concerns came up and participating in recovery were used by all survivors at different times during the phases of the disease.

Survivors in this study attempted to put the cancer in the background and try to get on with their lives. They did seem to have reminders of the cancer, particularly when the time came for follow-up appointments. This was also documented by Carter (1989) as she described her participants involved in a process of "going through." The stage of "moving on" is similar to what was observed in the present study.

Both Quigley (1989) and Maher (1982) note that fears of recurrence and risks of having a second cancer leave the survivor with an increased sense of vulnerability. Shanfield (1980) also described this same feeling of vulnerability in his work. When participants in this study were asked the questions about the consequences of having cancer, all identified their fears which related to recurrence or development of another cancer.

\section{Implications for practice}

Implications for nursing practice can be derived from the study findings but are offered only as tentative suggestions due to the limited sample size.

Nurses need to seize the opportunity to educate newly diagnosed cancer patients and their families about coping strategies and the possible benefits they may have for them. In doing this, nurses will be assisting patients as they begin the survival process. Nurses must also be aware that patients are individuals who have different experiences in their lives and thus may use differing coping strategies in order to deal with a cancer diagnosis. Although not addressed within this study, culture, race, age and life stage may be significant in determining the way one copes with and manages this illness.

The individual's meaning of the cancer experience should be taken into account when providing care. The individual concerns which emerge during the experience with cancer should be attended to. Nurses who are cognizant of how cancer can affect individuals at differing points in the life cycle may then be able to help patients cope with the immediate situation. In turn, this may ultimately help with long-standing difficulties.

Nurses should also help patients express their fears about the anxiety and uncertainty around the issue of recurrence (Mullen, 1985; Northouse, 1981; and Schmale et al., 1983). They can assist patients to develop healt hy strategies for coping with this fear. These strategies could include relaxation, self-help groups, exercise, and expression of fears.

Nursing curricula may need to be expanded to include course work in the areas of the cancer experience. Content pertinent to how individuals cope with the impact of life-threatening diseases, other than cancer, may also be useful. Course work needs to be expanded to include learning how to care, interviewing and communication skills, and allowing clients opportunities to talk about their experiences.

\section{Future research}

The numbers of cancer survivors are increasing due to advances in early detection and improved treatments, and there are many questions which future research in the area of cancer survivorship can address.

Nursing research needs to study the steadily increasing population of survivors. Qualitative research which explores the process of surviving would be most timely and beneficial for patients, families, and caregivers. Future descriptive studies with larger samples of 
cancer survivors in the area of coping strategies may further delineate these strategies, identify new ones, and reveal patterns.

Studies with survivors who have had similar diagnoses and treatment would be of interest in order to determine if the strategies they use change ower time or are different depending on the type of cancer. Other studies which deal specifically with survivors at different developmental stages could prove useful and elicit some interesting findings. Specific studies could look at what strategies survivors use to manage the uncertainties of recurrence and the anxiety that accompanies follow-up appointments. Future research should describe the coping strategies of significant others, friends, colleagues and employers who are in contact with long-term survivors. For instance, how do the employer and colleague view the return of the cancer survivor to the workplace? Do these individuals use specific strategies to deal with the cancer survivor?

Research into how the public, loved ones, family, friends, employers and professionals view the cancer survivor is needed. The American Cancer Society (Seffrin and Lamarine, 1987) has been instrumental in investigating public attitudes toward cancer, however research has not been documented on attitudes towards long-term survivors of cancer.

\section{References}

1. Benner, P. (1985). Quality of life: A phenomenological perspective on explanation, prediction, and understanding in nursing science. Advances in Nursing Science, 8(1), 1-14.

2. Cantor, R.C. (1980). And a time to live: Toward emotional well-being during the crisis of cancer. New York: Harper Colophon Book.

3. Carter, B.J. (1989). A phenomenological study of survivors of adult cancer. Unpublished doctoral dissertation, University of San Francisco, San Francisco.

4. Dirksen, S.R. (1989). Perceived well-being in malignant melanoma survivors. Oncology Nursing Forum, 16(3), 353-357.

5. Fernsler, J. Holcombe, J., and Pulliam, L. (1984). A survey of cancer nursing research. Oncology Nursing Forum, 11(4), 46-52.

6. Fiore, N. (1979). Fighting cancer - one patient's perspective. The New England Journal of Medicine, 300(6), 284-289.

7. Fisher, R. (1981). A patient's perspective on the human side of cancer. Proceedings of the Third National Conference on Human Values and Cancer. New York: American Cancer Society.

8. Gerlach. R.W., Gambosi, J.R. and Bowen, R.H. (1990). Cancer survivors' needs reported by survivors and their families. Journal of Cancer Education, 5(1), 63-70.

9. Grant, M.M. and Padilla, G.V. (1983). An overview of cancer nursing research. Oncology Nursing Forum, 10(1), 58-69.

10. Kaufman, D. (1987). Surviving cancer. Washington: Acropolis Books Ltd.

\section{Of special interest}

The 1991 CANO conference in Ottawa witnessed the birth of the first interest group to organize under the CANO umbrella. The Paediatric Oncology Nurse Interest Group came into being at the September conference. There was a healthy showing of paediatric nurses, representing four provinces, who attended the planning meeting. From this initial meeting a sub-committee was formed to do some strategic planning with regard to formalizing our interest group. We decided to dedicate our early efforts towards formulating a central roster of paediatric oncology nurses practicing across the country.

It is hoped that all nurses practicing in the field of paediatric oncology will be interested in this venture and will take the time to complete the "clip and mail" form in this issue of the CANO journal. There is no cost involved in adding your name to the roster.

Acknowledgement will be sent to you when your completed form has been received.

We are looking forward to an exciting future as a developing and dynamic interest group within the CANO organization.

Please help us to help each other.
11. Kennedy, B.J., Tellegen, A., Kennedy S., and Havernick, N. (1976). Psychological response of patients cured of advanced cancer. Cancer, 38, 2184-2191.

12. Leigh, S. (1989). Nurses supporting the survivorship movement. Innovations in Oncology Nursing, 5(4), 1, 7, 11.

13. Lewis, F.M. (1982). Experienced personal control and quality of life in late-stage cancer patients. Nursing Research, 3, 113-119. 14. Mullan, F. (1984). Re-entry: The educational needs of the cancer survivor. Health Education Quarterly, Supple. 10, 88-94. 15. Mullan, F. (1985). Seasons of survival: Reflections of a physician with cancer. The New England Journal of Medicine. 313(4), 270-273.

16. Neuman, B. (1989). The Neuman systems model (2nd ed.). Norwalk: Appleton and Lange.

17. Quigley, K.M. (1989). Adult cancer survivor: Psychosocial consequences of cure. Seminars in Oncology Nursing, 5(1), 63-69. 18. Schmale, A. H., Morrow, G. R., Schmitt, M. H., Adler, L. M., Enelow, A., Murawski, B. J., and Gates, C. (1983). Well-being of cancer survivors. Psychosomatic Medicine, 45(2), 163-169.

19. Scott, D. W. (1985). The research connection: Practice, research, theory. In Proceedings of the American Cancer Society Fourth cancer Nursing Research Conference (pp. 19-47). Englewood: American Cancer Society.

20. Sourkes, B. M. (1982). The deepening shade: Psychological aspects of life-threatening illness. Pittsburgh: University of Pittsburgh Press.

21. Weisman, A. D. (1979). Coping with cancer. New York: McGraw-Hill.

\section{The Paediatric Oncology Nurse Interest Group wants you...}

to complete this registration form so that a central roster of paediatric oncology nurses across Canada can be developed.

Name:

Institution/address:

Position held:

Number of years in paediatric oncology:

Area of interest or specialization:

Are you currently a member of CANO and/or your provincial oncology association?

yes no

Mail to: Annette Penney, Izaak Walton Killam Hospital for Children, 6 West Oncology Nursing Unit, 5850 University Avenue, Halifax, Nova Scotia, B3J 3 G9 